Eur. J. Clin. Chem. Clin. Biochem.

Vol. 29, 1991, pp. 749-752

(C) 1991 Walter de Gruyter \& Co. Berlin - New York

\title{
The Value of Laboratory Tests in Patients Suspected of Acute Appendicitis
}

\author{
By Marja P. van Dieijen-Visser ${ }^{1}, P . M . N . Y . H . G o^{2}$ and P. J. Brombacher ${ }^{1}$ \\ 1 Department of Clinical Chemistry \\ 2 Department of Surgery \\ De Wever Hospital, Heerlen, The Netherlands
}

(Received October 22, 1990/July 29, 1991)

Summary: The clinical usefulness of laboratory tests was examined in 258 patients admitted to the emergency room with the general practitioner's tentative diagnosis, acute appendicitis. Acute appendectomy was performed on 91 patients. Histological examination of the appendix confirmed the diagnosis in 69 cases (acute appendicitis 20 , phlegmonous appendicitis 36 , perforation 13 ). Seven patients with appendicular infiltrate were not subjected to operation but the diagnosis was clear from clinical examination. On close examination/ operation by the surgical team, 96 admitted patients were excluded from the primary diagnosis, acute appendicitis, and served as a control group.

Receiver Operating Characteristic curves (ROC-curves) showed that the sensitivity and specificity and hence diagnostic efficiency for total white blood cell count, number of segmented leukocytes and C-reactive protein concentration for the detection of acute appendicitis were higher than for erythrocyte sedimentation rate, $\alpha_{1}$ antiproteinase concentration and body temperature. We observed that when all three parameters, C-reactive protein, white blood cell count and segmented leukocytes, are within the normal range the diagnosis, acute appendicitis is highly unlikely.

The diagnostic value of the different laboratory parameters appears, moreover, to be highly dependent on the degree of inflammation/perforation and the development of appendicular infiltration. However, diagnostic efficiency can be improved, and unnecessary surgery prevented, by performance of an appropriately selected combination of laboratory tests combined with evaluation of clinical symptoms.

\section{Introduction}

Suspicion of appendicitis is the most common reason for an emergency surgical admission in the western world. Sometimes, it can be very difficult to obtain a correct diagnosis $(1,2)$. The inflammation can either be wrongly diagnosed or remain unrecognized. The diagnosis is based on the patient's history, physical examination and laboratory tests, and recently ultrasound has been recognized as a contributing technique (3). In order to avoid perforation a relatively high percentage of false-positive diagnoses is accepted, resulting in unnecessary surgery. Laboratory values contribute to the diagnostic process, but do not give absolute certainty $(2-10)$. Although various labora- tory tests have been proposed to overcome this problem, their value is uncertain and for the moment no laboratory investigation is of definite value in confirming the diagnosis, appendicitis. The number of abnormal test results increases with an advancing stage of the appendiceal inflammation found at operation (5). In patients with perforation or appendicular infiltrate the diagnosis is generally clear from clinical data and observation, making laboratory investigations superfluous. Laboratory values are, however, indispensable in the majority of patients where the clinical picture is not that clear. We therefore examined the diagnostic efficiency of the different laboratory parameters not only for the overall group, but also related to stages of the disease. 


\section{Patients}

Two hundred and fifty eight patients admitted to the emergency room with the gencral practitioner's presumptive diagnosis, acute appendicitis, were included in this study. Acute appendectomy was performed on 91 patients. Histological examination confirmed the diagnosis in 69 cases (Department of Pathology, Head Dr. Joh. Koudstaal). Seven patients with appendicular infiltrate were not operated on; the diagnosis was clear from clinical examination and observation. Patients with apparent different diagnoses (by the hospital surgical team), i. e. adnexitis, gastritis, cystitis etc. were eliminated from the study. Patients were classified as follows: Group 1 (total $n=96$ ) consisting of submitted patients where the diagnosis, acute appendicitis was rejected and who were not operated $(n=74)$, and patients with appendix sana $(n=22)$; Group 2 (total $n=56$ ) appendiceal inflammation $(n=20)$ or phlegmonous appendix $(n=36)$; Group 3 perforation $(n=13)$; Group 4 appendicular infiltrate, $(n=7)$.

\section{Methods}

Laboratory tests were performed on blood samples obtained on admission to the emergency room. Body temperature was also recorded on admission. White blood cell count and segmented leukocytes were determined on the Technicon H-6000 using venous blood collected in EDTA. Erythrocyte sedimentation rate was performed according to Westergren (Haematological Department, Head Dr. J. W. J. van Wersch). Blood samples for measurement of acute phase proteins were centrifuged immediately after collection and clotting. The sera were stored at $-20^{\circ} \mathrm{C}$ until examination. C-reactive protein and $\alpha_{1}$ antiproteinase were measured immunochemically by turbidimetry on a Cobas Fara analyser (Roche), using antibodies from ATAB (Atlantic Antibodies Inc.) and standards from Behring (ORCE02) for the $\alpha_{1}$-antiproteinase determination.

\section{Statistics}

Receiver operating characteristic (ROC) curves are graphical presentations of pairs of sensitivity and specificity, when taking different cut-off values to determine positivity of the test. The ROC-curve farthest to the upper left corner belongs to the best discriminating test (see figures).

\section{Results}

ROC-curves were constructed to evaluate and compare the usefulness of the different parameters as a predictive test for the different stages of appendicitis. Figure 1a presents sensitivity-specificity diagrams for the detection of acute appendicitis for white blood cell count, segmented leukocytes, C-reactive protein, $\alpha_{1}$-antiproteinase and body temperature (disease groups $2-4$, taking group 1 as the reference population). Figure $1 \mathrm{~b}$ presents sensivitity-specificity diagrams for the detection of acute appendicitis and phlegmonous appendicitis, i.e. those forms that are most difficult to diagnose from clinical signs (disease group 2 vs. reference group 1). Figure 1c presents sensitivity-specificity diagrams for the detection of perforation and appendicular infiltrate, where the clinical presentation of the disease is mostly clear
Tab. 1. Sensitivity, specificity and predictive values (PV) for combinations of tests in the diagnosis of acute appendicitis (groups 2, 3, 4 vs reference group 1).

$\mathrm{WBC}=$ white blood cell count; $\mathrm{CRP}=\mathrm{C}$-reactive protein

\begin{tabular}{|c|c|c|c|c|}
\hline Combination of tests & $\begin{array}{l}\text { Sensi- } \\
\text { tivity , } \\
(\%)\end{array}$ & $\begin{array}{l}\text { Speci- } \\
\text { ficity } \\
(\%)\end{array}$ & $\begin{array}{l}\mathrm{PV}+ \\
(\%)\end{array}$ & $\begin{array}{l}\text { PV- } \\
(\%)\end{array}$ \\
\hline $\mathrm{WBC}>10$ and CRP $>12$ & 56 & 93 & 86 & 73 \\
\hline$W B C>10$ or $C R P>12$ & 97 & 55 & 63 & 96 \\
\hline $\begin{array}{l}\text { WBC }>10 \text { and CRP }>12 \\
\text { and segmented granu- } \\
\text { locytes }>70 \%\end{array}$ & 22 & 99 & 94 & 62 \\
\hline $\begin{array}{l}\text { WBC }>10 \text { or CRP }>12 \\
\text { or segmented granu- } \\
\text { locytes }>70 \%\end{array}$ & 99 & 50 & 61 & 98 \\
\hline
\end{tabular}

(disease groups 3 and 4 vs. reference group 1). Table 1 presents sensitivity, specificity and predictive values for combinations of tests. The combinations are based either on an "and rule", i. e. all tests exceed the upper reference value, or on an "or rule" i. e. any one of the individually linked tests is higher than the upper limit of the reference interval.

\section{Discussion}

Acute appendicitis continues to present diagnostic problems. Marchand et al. (2) compared the diagnostic efficiency of white blood cell count, C-reactive protein and fever in patients suspected of acute appendicitis, where the final diagnosis was obtained on a histological basis. The diagnostic efficiency of the cytochemically determined neutrophil count and white blood cell count appeared to be better than that of manually counted neutrophils and C-reactive protein. Erythrocyte sedimentation rate and $\alpha_{1}$-antiproteinase were not included in their study: Van Lente (4) compared the diagnostic sensitivity of different acute phase proteins for acute appendicitis. Higher sensitivities were observed for C-reactive protein and $\alpha_{1}$-antiproteinase than for acidic $\alpha_{1}$-glycoprotein, haptoglobin and ceruloplasmin. Antonsen (10) observed a better diagnostic efficiency for blood leukocytes and neutrophils than for elastase and C3d. From our study the best diagnostic efficiency was also obtained for blood leukocytes and neutrophils. Elastase was not measured, but its contribution is far less than that of blood leukocytes, as can be concluded from the results of Antonsen (10). From our study it can be concluded that the diagnostic sensitivity of the different laboratory parameters depends very much on the stage of appendicitis, i.e. composition of the examined population. This makes comparíson with other studies, 

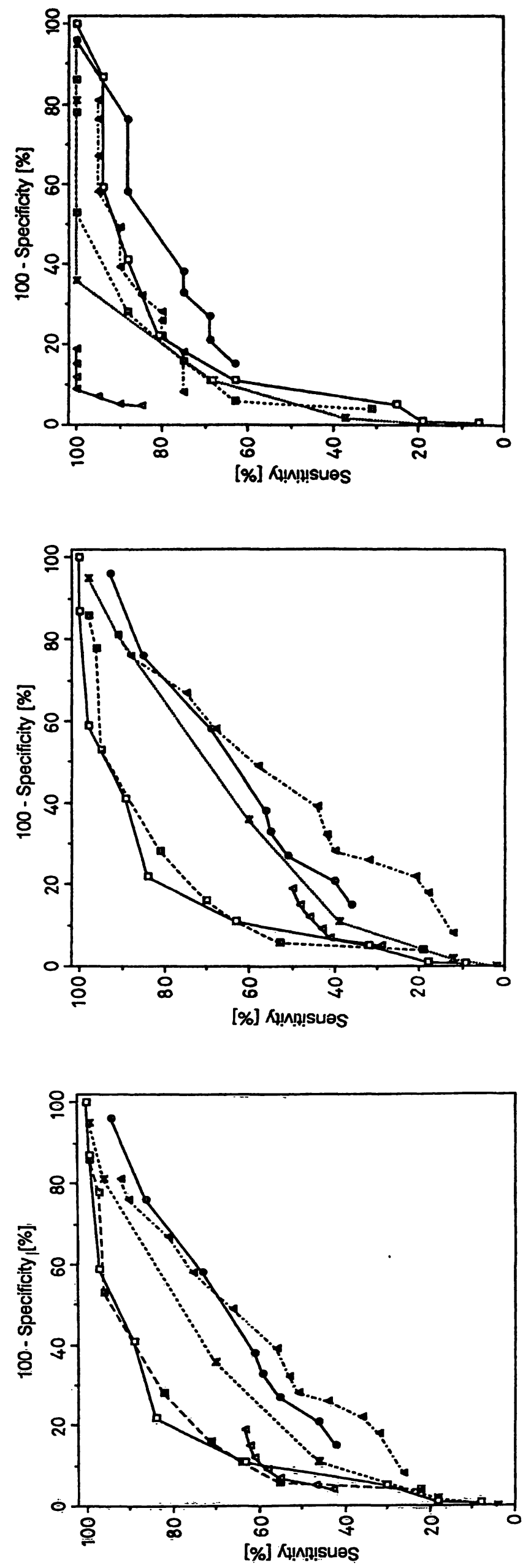

告

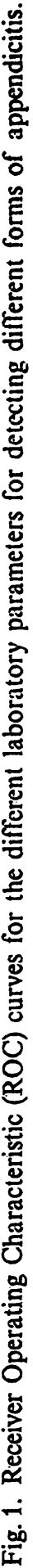

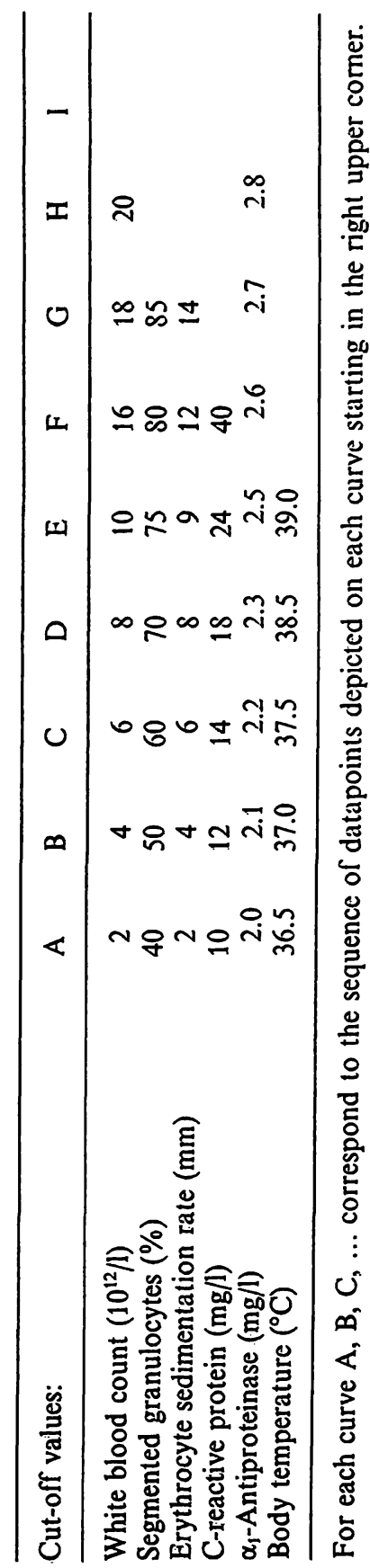


where no classification of appendicitis (appendicitis, phlegmonous, perforation and appendicular infiltrate) is made, very difficult. Laboratory data are most important and they make a significant diagnostic contribution when the history of disease and clinical signs are confusing, which is especially so in acute and phlegmonous appendicitis (group 2). Singh et al. (6) recently advocated determinations of plasma serotonin levels in confirming or excluding early acute appendicitis, where physical signs are equivocal. This however, meets practical problems in an emergency case. In patients with perforation or appendicular infiltrate (groups 3,4 ) the clinical picture is clear and consequently laboratory parameters are less indispensable. From the present study it can be concluded that diagnostic efficiency of laboratory parameters greatly depends on the stage of disease. As far as the determination of acute phase proteins is concerned, it can be concluded that C-reactive protein concentration in serum is the laboratory parameter of choice, giving better results compared with erythrocyte sedimentation rate and $\alpha_{1}$-antiproteinase. Segmented leukocyte counts e.g. have low diagnostic value in the group with perforation or appendicular infiltrate, but should be performed in the milder and more difficult to diagnose forms. It is true that the morbidity and mortality of missing a case of acute appendicitis with subsequent abscess formation and rupture far outweigh the morbidity and mortality associated with removal of a normal healthy appendix, due to misdiagnosis $(2,10)$. Nevertheless the diagnostic procedure should be as reliable as possible to avoid unnecessary surgery. The test combination of white blood cell count, $\mathrm{C}$-reactive protein and segmented leuko-

\section{References}

1. Jess, P. (1983) Acute appendicitis: Epidemiology, diagnostic accuracy and complications. Scand. J. Gastroenterol. 18, $161-163$.

2. Marchand, A., Van Lente, F. \& Galen, R. S. (1983) The assessment of laboratory tests in the diagnosis of acute appendicitis. Am. J. Clin. Pathol. 80, 369-374.

3. Puylaert, J. B. C. M. (1988) The use of ultrasound in patients with clinical signs of appendicitis. Thesis Leiden University Netherlands.

4. Van Lente, F. \& Galen, R. S. (1984) Acute-phase proteïns in appendicitis. Clin. Chem. 30, 160.

5. Mikaelsson, C. \& Arnbjornsson, E. (1984) The value of Creactive proteîn (CRP) determinations in patients with suspected acute appendicitis. Ann. Chir. Gynaecol. 73, 281 284.

6. Singh, M. S., Dean, H. G., de Dombal, F. T., Wilson, D. H. \& Flowers, M. W. (1988) Concentrations of serotonin in plasma a test for appendicitis? Clin. Chem. 34, 25722574. cytes gives positive results with $99 \%$ sensitivity. This means that when all three tests are within the reference interval the diagnosis acute appendicitis is very unlikely, as is also illustrated by the PV-value of $98 \%$. The patient should therefore not be operated upon. From our group with diagnosed appendix sana on histological examination, nine patients could have been put under clinical observation, instead of being operated, because $\mathrm{C}$-reactive protein, white blood cell count and segmented leukocytes were all within the reference interval. Although the mentioned parameters can be elevated in many inflammatory processes, the reported high sensitivity is found in a population that has been selected for suspected acute appendicitis on the basis of disease history and clinical symptoms. This should of course be kept in mind when discussing the value of these laboratory tests in diagnosing this special disease. The consequent application of our results is that in any case of acute appendicitis, where diagnosis is not absolutely clear by clinical observation, the counting of total white blood cells, segmented leukocytes and the determination of serum Creactive protein concentration must be performed. This will lead to better diagnosis and will contribute to the prevention of unnecessary surgery in a number of cases, which has been the aim of our study.

\section{Acknowledgement}

Measurements of white blood cell count, segmented leukocytes and erythrocyte sedimentation rate were performed under the guidance of $\operatorname{Dr} J$. W. J. van Wersch, head Department of Haematology. Thanks are also due to Chantal Wetzels and Fia Joosten-Deckers for technical assistance.
7. Peltola, H., Ahlqvist, J., Rapola, J., Rasanen, J., Louhimo, I., Saarinen, M. \& Eskola, J. (1986) C-reactive proteïn compared with white blood cell count and erythrocyte sedimentation rate in the diagnosis of acute appendicitis in children. Acta Chir. Scand. 152, 55-58.

8. Van Dieijen-Visser, M. P., Go, P. M. N. Y. H., Munting, J. D. K. \& Brombacher, P. J. (1989) The value of laboratory investigations in patients suspected of acute appendicitis. Biologie prospective (Galteau, M. M., Siest, G. \& Henny, J., eds.) John Libbey Eurotext, Paris, pp. $311-314$.

9. Jacob, E. T., Bar-Nathan, N. \& Iuchtman, M. (1975) Errorrate factor in the management of appendicitis. Lancet 2 , 1032.

10. Antonsen, S. \& Qvist, N. (1988) Evaluating blood leukocytes, blood neutrophils and plasma elastase in acute appendicitis. Theor. Surg. $3,17=22$.

Dr. M. P. van Dieijen-Visser

Department of Clinical Chemistry

De Wever Hospital

P. O. Box 4446

NL-6401 CX Heerlen' 